\title{
Colorectal Cancer Peptide Vaccine PolyPEPI1018
}

National Cancer Institute

\section{Source}

National Cancer Institute. Colorectal Cancer Peptide Vaccine PolyPEPI1018. NCI

Thesaurus. Code C154278.

A peptide cancer vaccine consisting of a combination of six synthetic polypeptides

directed against cancer testis antigens (CTAs) frequently expressed in colorectal cancers, with potential antineoplastic and immunostimulatory activities. Colorectal cancer peptide vaccine PolyPEPI1018 potentially elicits a cytotoxic T-lymphocyte response against colorectal tumors expressing the CTAs associated with the vaccine, which may result in a reduction in tumor cell proliferation. 